DE

M E D I C I N A

T R O P I C A L

$\mathrm{DE}$

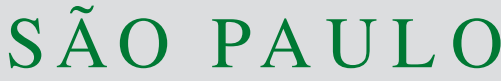

JOURNAL OF THE SÃO PAULO INSTITUTE OF TROPICAL MEDICINE

(1) Universidade Federal do Rio de Janeiro, Hospital Universitário Clementino Fraga Filho, Serviço de Dermatologia, Rio de Janeiro, Rio de Janeiro

(2) Universidade Federal do Rio de Janeiro, Hospital Universitário Clementino Fraga Filho, Curso de Especialização em Dermatologia, Rio de Janeiro, Rio de Janeiro

(3) Universidade Federal do Rio de Janeiro, Hospital Universitário Clementino Fraga Filho, Laboratório de Virologia, Rio de Janeiro, Rio de Janeiro

Correspondence to: Nurimar C. Fernandes Universidade Federal do Rio de Janeiro, Hospital Universitário Clementino Fraga Filho, Serviço de Dermatologia, Rua Professor Rodolpho Paulo Rocco, nำ 255, 5aar, Cidade Universitária, CEP 21941-913, Rio de Janeiro, RJ, Brazil Tel: $+55213938-2580$

E-mail: nurimarfernandes@terra.com.br

Received: 3 October 2016

Accepted: 31 March 2017

\section{Refractory pemphigus foliaceus associated with herpesvirus infection: case report}

\author{
Nurimar C. Fernandes ${ }^{1}$, Heloisa Rampinelli ${ }^{2}$, Leandro Magalhães de Souza ${ }^{3}$, \\ Maria Angélica A. M. Guimarães ${ }^{3}$
}

\section{ABSTRACT}

Pemphigus foliaceus (PF) is an autoimmune disease characterized by blistering of the skin. Infections caused by members of the herpesviridae family have been suggested as a possible triggering factor for pemphigus vulgaris (PV), but not for PF. The present study aimed to investigate the presence of Human herpesvirus (types 1,2,3) in corticosteroid refractory skin lesions from a patient with $\mathrm{PF}$, by a Polymerase chain reaction (PCR) assay. The sample collected from cutaneous blisters has tested positive for herpes simplex virus type 1 (HSV1) after sequence analysis of the amplified viral genomic segment. The study concluded that when PF patients present corticosteroid or immunosuppressants refractory lesions, herpetic infection should be considered.

KEYWORDS: Pemphigus. Human Herpesvirus 1. Human Herpesvirus 2. Polymerase chain reaction.

\section{INTRODUCTION}

The term pemphigus refers to a group of autoimmune blistering diseases of skin and mucous membranes that are characterized histologically by intraepidermal blisters due to acantolysis, i.e., separation of epidermal cells from each other and immunopathologically by in vivo bound and circulating $\operatorname{IgG}$ directed against the cell surface of keratinocytes. Pemphigus can be divided into four major types: vulgaris (PV), foliaceus (PF), paraneoplastic and IgA pemphigus. In PV, the blister occurs in the deeper part of epidermis, just above the basal layer and in PF, the blister is in the granular layer. Also called endemic PF, fogo selvagem is a disease that is clinically, histologically and immunopathologically the same as sporadic PF in any individual patient; it is endemic in rural areas of Brazil especially along inland riverbeds. A study of potential environmental risk factors has also implicated the bite of black fly - simulium - as a vector of the disease.

Kaposi's varicelliform eruption (eczema herpeticum) results from a widespread infection following inoculation of virus into skin, damaged by eczema. It is usually a manifestation of primary Human Herpesvirus type 1 infection $\left(\mathrm{HHV}_{1}\right)$ (herpes simplex virus 1 / HSV1) in a patient with atopic dermatitis. However other skin conditions can also be complicated by cutaneous dissemination of Human herpesvirus type 1, type 2 (herpes simplex virus $2-\mathrm{HSV}_{2}$ ) and type 3 (varicella zoster virus - VZV). Some of the known predisposing conditions include various bullous disease of the skin, particularly when patients are receiving immunosuppressive therapy. In eczema herpeticum (Kaposi's varicelliform eruption) vesicles develop in large number over 
the areas previously compromised and become pustular, and markedly umbilicated. The severity of this infection ranges from mild to fatal, with dissemination of lesions; patients commonly have high fever and adenopathy ${ }^{1,2}$.

Several reports have pointed out to the participation of viral infections in the triggering and activating the PV. Some authors consider that viruses might be involved in acute exacerbation of PV in some patients ${ }^{3,4}$.

The aim of this study was to look for the presence of Human Herpesvirus (HHV) in persistent lesions of a patient with recurrent PF, refractory to treatment with different immunosuppressant drugs.

\section{CASE REPORT}

A 57-year-old patient with diagnosis of pemphigus foliaceus (flaccid vesicles, erosions, crusts and desquamation on scalp, face and trunk) confirmed through a skin biopsy histopathology of an early blister located in the granular layer. Since 2013 he has been submitted to oral prednisone $(1 \mathrm{mg} / \mathrm{kg} /$ day) (Figure 1). After an initial control of the disease, the following drugs were added for relapsing: cyclophosphamide pulse therapy (14 pulses), oral hydroxycloroquine (400 mg/day for two years), pulse therapy with dexamethasone (five pulses), immunoglobulin (four cycles). During the treatment the patient experienced hypertension and diabetes mellitus. In December 2013 he developed an acute Kaposi's varicelliform eruption treated with acyclovir $(10 \mathrm{mg} / \mathrm{kg} / \mathrm{EV}$ each eight hours for 14 days). In 2016, examination of a Gram-stained smear of aspirated material from the purulent bulla (Figure 1, B1) yielded a positive culture for Staphylococcus aureus; two swabs for PCR were taken from non purulent bullous lesions in the trunk (Figure 1, B2, B3).

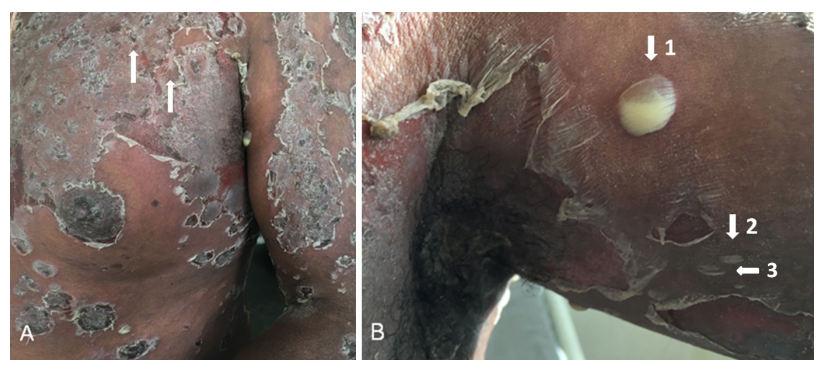

Figure 1 - A) Desquamation and crusts in the trunk; B) 1- purulent bulla, 2,3- not umbilicated clear blisters.

Clinical specimens were submitted to nucleic acid extraction by using a commercial kit (RTP virus DNA Mini kit, Invisorb Stratek, USA). A Sybr Green real-time PCR assay ${ }^{5}$ was used to detect the presence of Human Herpesvirus 1, 2, $3\left(\mathrm{HHV}_{1}, \mathrm{HHV}_{2}, \mathrm{HHV}_{3}\right)$ and a nested
PCR assay ${ }^{6}$ was used to detect HSV1 and 2 DNA. We detected the presence of Human Herpesvirus (HHV), in both PCR assays (Figure 2), but we could not distinguish between HSV1 or 2 (herpes simplex virus 1 or herpes simplex virus 2). HSV PCR products were then purified by GE Healthcare commercial kit and the fragments (sense and anti-sense) were sequenced using the Big Dye ${ }^{\mathrm{TM}}$ terminator sequencing protocol (Applied Biosystems Inc., Foster City, CA). The amplified HSV DNA segments were subjected to phylogenetic analysis (ClustalW and MEGA programs). The sequences available in GenBank were used as references. The analysis of sequence genomic segments in both clinical materials showed the presence of Human Herpesvirus type $1\left(\mathrm{HHV}_{1}-\mathrm{HSV}_{1}\right)$.

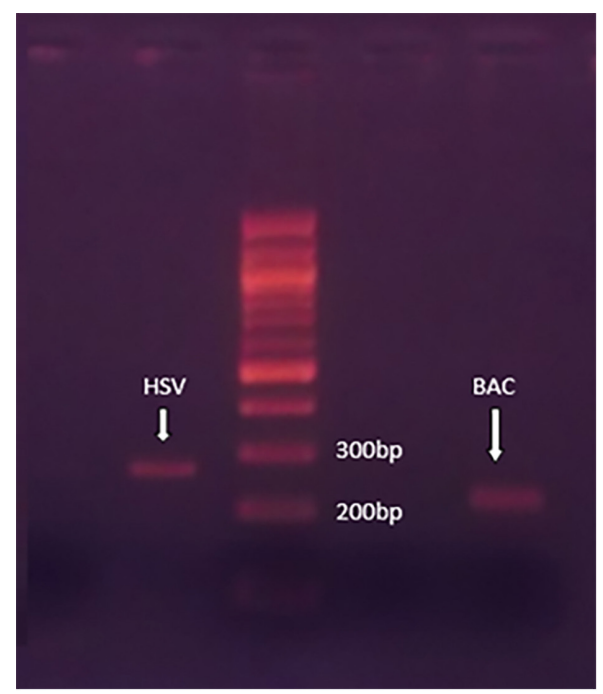

Figure 2 - Ethidium bromide stained agarose gel showing the 244 bp HSV amplification product and the 220 bp BAC amplification product (segment of the human beta-Actin gene used as PCR positive control) and the size marker $100 \mathrm{bp}$ (Invitrogen).

\section{DISCUSSION}

Fogo selvagem occurs often in children and young adults, unlike sporadic PF which is a disease of mostly middle-aged and older patients. PF lesions are scaly, crusted erosions on an erythematous base scattered in a seborrheic distribution including the face, scalp and upper trunk. The primary small flaccid blisters are difficult to find. In contrast to patients with PV, only very rarely, if ever, PF has mucous membranes involvement.

The possible etiologic role of virus infection in the development and/ or exacerbation of PV has been reported. The association of PV and HSV has been described in Brazil, as well as in the other countries ${ }^{7,8,9}$. Although the role of HSV infections in PV is not completely understood, it is quite clear the importance of its detection. 
To our knowledge, this is the first report showing the presence of HSV in a PF lesion, refractory to conventional treatment.

There are possible explanations for the presence of $\mathrm{HSV}$ in the skin lesion. One of them is the lack of a normal epithelial defense in the pemphigus lesion that associated to the use of immunosuppressive therapy should facilitate secondary skin virus infections ${ }^{7}$. According to other reports concerning viral infections, in preexisting PV lesions ${ }^{4}$, HSV could be an opportunistic infection ${ }^{10}$. A question still remains: could HSV be involved in acute exacerbation of the disease? We did not find typical grouped vesicles or umbilicated ones in this patient. We observed relapses and unresponsiveness to adequate immunosuppressive therapy which drew our attention to the possibility of a concomitant viral complication. It is worth to mention that it was not possible to evaluate the exclusive role of acyclovir in the treatment of the patient since antibiotic was given, at the same time, for superimposed bacterial blister infection, a very common complication in pemphigus.

In one case series ${ }^{7}$ the authors claimed that they discovered a superinfection with HSV1 or HSV2 occurring in the clinical setting of varied autoimmune bullous dermatoses, including various subtypes of pemphigus. They were diagnosed as having Kaposi varicelliform eruptions without the description of characteristic morphology of grouped umbilicated vesicles. The patients had HSV positivity in viral PCR or culture from swabs of skin affected by bullous disease. Then, there are two possible scenarios: a simultaneous occurrence of herpesvirus infection in bullous lesions or a true VKE.

In the present case typical HSV lesions - multiple, grouped small $(1-3 \mathrm{~mm})$, round and umbilicated blisters - arising from inflamed skin were not observed. Only by PCR performed on clear blisters samples chosen by chance, it was possible to identify those co-infections appearing together with the flare up of PF.

The subcorneal pustulosis dermatosis must be differentiated from impetigo contagiosa, dermatitis herpetiformis, PF and acute generalized pustulosis. In this case, this diagnosis is ruled out by the presence of bacteria in the pustule and the effectiveness of systemic antibiotic therapy.

\section{CONCLUSIONS}

The refractoriness to conventional therapy in pemphigus foliaceus should raise the possibility of a HSV skin infection, so that laboratory investigation must be performed for the detection of viruses with tropism to skin.

\section{REFERENCES}

1. Lehman JS, el-Azhary RA. Kaposi varicelliform eruption in patients with autoimmune bullous dermatoses. Int J Dermatol. 2016;55:e136-40.

2. Nath AK, Sori T, Thappa DM. A case series of Kaposi's varicelliform eruption in dermatology in-patients in a tertiary care center. Indian J Dermatol. 2011;56:110-5.

3. Tufano MA, Baroni A, Buommino E, Ruocco E, Lombardi ML, Ruocco V. Detection of herpesvirus DNA in peripheral blood mononuclear cells and skin lesions of patients with pemphigus by polymerase chain reaction. Br J Dermatol. 1999;141:10339.

4. Schlüpen EM, Wollenberg A, Hänel S, Stumpenhausen $\mathrm{G}$, Volkenandt M. Detection of herpes simplex virus in exacerbated pemphigus vulgaris by polymerase chain reaction. Dermatology. 1996;192:312-6.

5. Sugita S, Shimizu N, Watanabe K, Mizukami M, Morio T, Sugamoto Y, et al. Use of multiplex PCR and real-time PCR to detect human herpes vírus genome in ocular fluids of patients with uveitis. Br J Ophthalmol. 2008;92:928-32.

6. Kawada J, Kimura H, Ito Y, Hoshino Y, Tanaka-Kitajima N, Ando $\mathrm{Y}$, et al. Comparison of real-time and nested PCR assays for detection of herpes simplex virus DNA. Microbiol Immunol. 2004;48:411-5.

7. Caldarola G, Kneisel A, Hertl M, Feliciani C. Herpes simplex infection in pemphigus vulgaris: clinical and immunological considerations. Eur J Dermatol. 2008;18:440-3.

8. Oliveira DP, Moura HH, Janini ME, Fernandes NC, Santos N. Diagnosis and treatment of persistent oral lesions caused by herpesvirus in a patient with pemphigus vulgaris. Int $\mathrm{J}$ Dermatol. 2011;50:335-9.

9. Brandão ML, Fernandes NC, Batista DP, Santos N. Refractory pemphigus vulgaris associated with herpes infection: case report and review. Rev Inst Med Trop Sao Paulo. 2011;53:1137.

10. Nikkels AF, Delvenne P, Herfs M, Pierard GE. Occult herpes simplex virus colonization of bullous dermatitides. Am J Clin Dermatol. 2008;9:163-8. 